and had to be hauled up, occasionally, according to Scoresby, with broken jaw-bones. A log-book, dated 1871, now in the Hull Museum, contains the following entry: "June 25th (Lancaster Sound): Killed a whale which died at the bottom in 600 fathoms of water".

8, Hartley Road,

Exmouth.

Nov. 17.

1 "The Diving Powers of Whales", Naturalist, December 1932. "Aretic Regions", vol. 11, p. 173 and p. 389 .

\section{Vision in the Ultra-Violet}

WrTH regard to the discussion which has been taking place in NATURE recently ${ }^{1}$, the following observations may be of interest. In 1929, whilst working at the National Institute for Medical Research, Hampstead, with T. C. Angus, in the course of which we used, incidentally, a double monochromator, and whilst we were fitting this up, we decided to try on ourselves how far we could see into the ultra-violet. We decided that one of us could see the $\lambda 3130$, and the other could not see shorter than $\lambda 3650$ in the mercury spectrum. Another young physicist could see $\lambda 3130$ quite easily. An elderly man could only see $\lambda 3650$.

I have just repeated these observations. I can see $\lambda 3130$ quite easily, as can an assistant of mine and a youth who works in the clinic. Only a single monochromator was used for this purpose; this is a Hilger monochromator for the ultra-violet, and as Fabry $^{2}$ says, there is always a certain amount of background but this remains constant as the wavelength drum is rotated slightly. This later procedure brings the line on to and removes it from the collimator slit. Thus the line can be picked out against the background. The $\lambda 3130$ line appears as a dark violet colour much the same as $\lambda 3650$. Since people varying from fifteen to thirty years of age are able to get the sensation of sight with $\lambda 3130$, it does not seem to be the prerogative of extreme youth.

$$
\text { St. John Clinic and }
$$

H. J. TAYLOR.

Institute of Physical Medicine, Ranelagh Road, London, S.W.1. Nov. 26.

\section{${ }^{1}$ NATURE, 134, 416, Sept. 15, 1934.}

INATURE, 134, 736, NOv. 10, 1934.

\section{Oxidation-Reduction Potentials of Hypoxanthine $\vec{\sim}$ Xanthine and Xanthine $\approx$ Uric Acid}

IN a recent paper, D. E. Green ${ }^{1}$ published values of the potentials of the systems hypoxanthine $\rightleftarrows$ uric acid, xanthine $\neq$ uric acid, which I had already determined ${ }^{2}$.

Green claims to be the first to have demonstrated the reversibility of the system hypoxanthine $\rightleftharpoons$ uric acid. He states this, because my data are based on measurements made on equimolecular mixtures of hypoxanthine and uric acid, and consequently the constancy of the normal potential when the proportions of the constituents of the system are varied is not evident. Green asserts this, in spite of the fact that I have shown that the same state of equilibrium (the same potential) is found, whether hypoxanthine is oxidised, or uric acid is reduced. It seems to me then that the curve presented in my work leaves no doubt as to the reversibility of the system.
Green also states that I did not justify the assignment of the value of the number of equivalents in the formula :

$$
E_{h}=E_{0}-\frac{R T}{4 F} \ln \frac{[H x]}{[\bar{U}]}
$$

where $E_{0}$ is the normal potential, [Hx] the activity of hypoxanthine, and $[U]$ the activity of uric acid. It is, however, not at all difficult to see that if the reaction taking place in the galvanic cell is an oxidation of hypoxanthine into uric acid, and that this reaction is reversible (as I have shown it to be), then it follows that the above equation is a necessary consequence of thermodynamics. I did not consider it useful to insist on its validity in a preliminary note. Moreover, this equation does not at all imply equality of the levels of energy at which the four hydrogens are exchanged, since only the initial state and the final state of the constituents of the reaction are to be taken into consideration.

Finally, if I have neglected the dismutation discovered by Bach and Michlin, I have done so because Wieland was not able to confirm their findings. I quite agree with Green that the short duration of Wieland's experiments may explain why the dismutation of xanthine to hypoxanthine and uric acid was not observed. But I should like to point out that if such a dismutation does exist (in any proportion whatsoever), it would not at all affect my results since the ratio $[H x] /[U]$ remains equal to 1 when two molecules of xanthine are formed at the expense of one molecule of hypoxanthine and one molecule of uric acid.

Thus, no objection could be made as to the value, which I found for the normal potential of the system hypoxanthine $\rightleftarrows$ uric acid. It is :

$$
E^{\prime}{ }_{0}=-0.410 \text { volt at } 38^{\circ} \mathrm{C} \text {. and at } p \mathrm{H}=7.31
$$

(value calculated from my data), or

$$
{E^{\prime}}_{0}=-0 \cdot 399 \text { volt at } 30^{\circ} \mathrm{C} \text {. and at } p \mathrm{H}=7 \cdot 31
$$

(value calculated from the temperature coefficient that I have later established).

This value is identical with the theoretical one given by Green, namely, $-0 \cdot 400$.

As for the system xanthine $\rightarrow$ uric acid, the dismutation does bring about a correction for the value of $E^{\prime}{ }_{0}$ but it is inferior to the experimental errors if Bach and Michlin's figures are used. If, however, we apply the method of calculation that Michaelis has shown in his well-known work on two-step oxidations, and making use of Green's figures, we arrive at a new value for the dismutation constant. This value should be taken into consideration, although the resulting variation, when applied to equimolecular mixtures, is rather small.

Applying this correction, the value of the normal potential of the system xanthine $\rightleftharpoons$ uric acid will then differ from the one that $I$ have indicated by -0.0048 volt at $p H=7 \cdot 65$.

D. E. Green's confirmation of the existence of a dismutation process is therefore of interest. It entails a correction of the same order as the one brought about by the ionic concentration effect, which I have studied in detail in a memoir actually in press. Institut de Biologie physico-chimique, Sabina Finittit.

$$
\text { Paris. }
$$

\footnotetext{
1 Biochem. J., 28, No. 4, 1550; 1934.

Compt. rend. Acad. Sci., 197, 1212; 1933. 198, $930 ; 1934$.
} 